\title{
SISTEM INFORMASI PENGELOLAAN PASAR CEMARA BANJARMASIN BERBASIS WEB
}

\author{
Dian Agustini ${ }^{1)}$ Muthia Farida ${ }^{2)}$ \\ ${ }^{1}$ Fakultas Teknologi Informasi, Universitas Islam Kalimantan \\ Email : dian.ftiuniskabjm@gmail.com \\ ${ }^{2}$ Fakultas Teknologi Informasi, Universitas Islam Kalimantan \\ Email : Muthiafarida59@gmail.com)
}

\begin{abstract}
ABSTRAK
Sistem informasi di Pasar Cemara yang digunakan masih bersifat manual sehingga kesulitan dalam menyebarkan informasi terkait dengan pasar, pencarian data toko yang belum membayar uang retribusi, lokasi toko yang masih kosong, serta letak lokasi toko pedagang yang tidak tertata dengan rapi yang menyebabkan calon pembeli kesulitan ketika ingin berkunjung ke toko yang dituju. Tujuan penelitian ini adalah untuk membantu pengelolaan pasar yang terkomputerisasi. Metode yang digunakan pada penelitian ini adalah Waterfall yang mempunyai enam tahapan yaitu: Rekayasa dan Pemodelan Sistem (System Engineering), Analisa Kebutuhan Perangkat Lunak (Analysis), Perancangan Perangkat Lunak (Design), Pengkodean (Coding), Pengujian Perangkat Lunak (Testing), Pemeliharaan Perangkat Lunak (Maintenance). Teknik testing sistem menggunakan teknik Blackbox. Dan hasil akhir berupa Sistem Informasi Pengelolaan Pasar Cemara Banjarmasin Berbasis Web, diharapkan dengan adanya sistem tersebut dapat membantu dalam pengelolaan Pasar Cemara Banjarmasin.
\end{abstract}

Kata Kunci : Sistem,Retribusi Pasar,Unified Modelling Language (UML), PHP, MySQL

\section{PENDAHULUAN}

Pada Cemara Banjarmasin sistem pengelolaan Kios/Toko yang ada pada pasar Cemara Banjarmasin menggunakan sistem sewa, dimana kios/toko tersebut disewakan kepada pedagang dan dibayar setiap setahun atau sebulan sekali kepada pengelola pasar atau Disperindag (Dinas Perindustrian Dan Perdagangan) Banjarmasin. Data pedagang, status/biaya sewa, barang yang dijual dan data harga akomodasi serta Denah Lokasi Pasar merupakan laporan yang wajib informasikan kepada Kepala Dinas dan Pedagang serta pembeli yang bertujuan agar pengelolaan pasar semakin optimal dan pedagang ataupun pembeli dapat mengetahui informasi pasar dengan jelas.

Sistem yang berjalan saat ini masih menggunakan sistem yang manual yaitu data yang dikumpulkan hanya direkap dalam Microsoft excel. Belum ada sebuah sistem informasi berupa denah pasar yang menampilkan infromasi blok-blok pasar serta data pedagang dan jenis barang jualan yang dijual sehingga pembeli terkadang harus bolakbalik mengelilingi pasar untuk mencari barang yang diperlukannya.

\section{METODE PENELITIAN}

Metode yang digunakan pada penelitian ini adalah Waterfall yang mempunyai enam tahapan yaitu : Rekayasa dan Pemodelan Sistem (System Engineering), Analisa Kebutuhan Perangkat Lunak (Analysis), Perancangan Perangkat Lunak (Design), Pengkodean (Coding), Pengujian Perangkat Lunak (Testing), Pemeliharaan Perangkat Lunak (Maintenance). Teknik testing sistem menggunakan teknik Blackbox.

\section{HASIL DAN PEMBAHASAN}

Implementasi Sistem yang pertama adalah gambaran dari aplikasi atau program yang telah dibuat.

1. Activity Diagram Input data Merupakan diagram aktivitas input data.

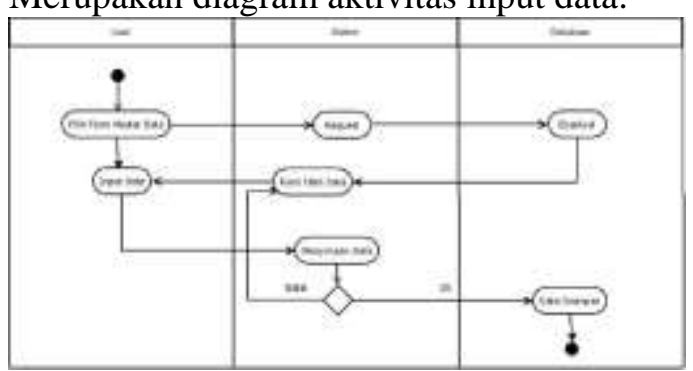


Gambar 1. Activity Diagram Input Data

2. Class Diagram Pedagang

Merupakan diagram kelas Pedagang

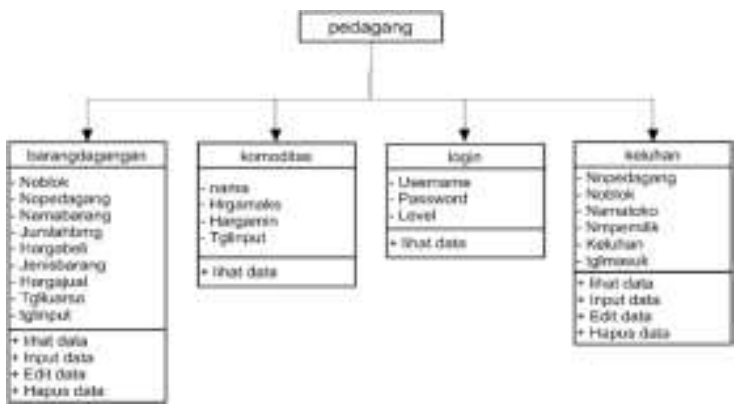

Gambar 2. Class Diagram Pedagang

3. Form Inout Data Jualan

Merupakan form untuk mengisi data jualan pedagang

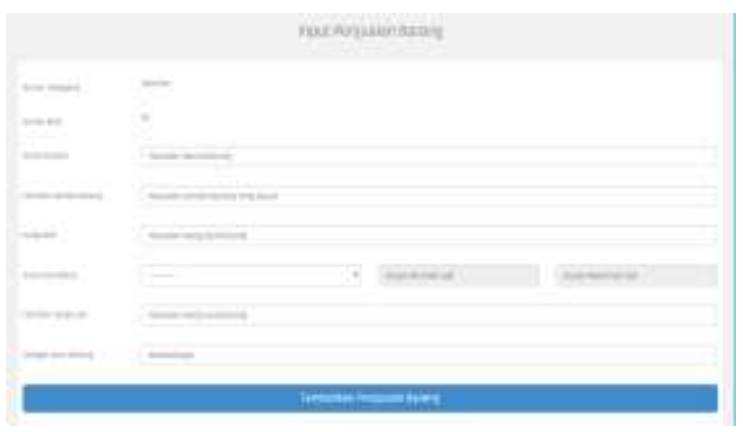

Gambar 3. Form Input Data Jualan

4. Form Input Data Komoditas Merupakan Form Mengisi Data Komoditas

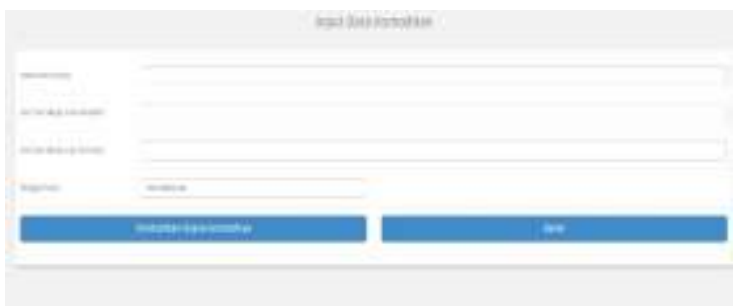

Gambar 4. Form Input Data Komoditas

5. Laporan Retribusi Pasar

Merupakan hasil laporan dari retribusi pasar

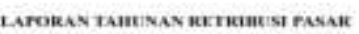

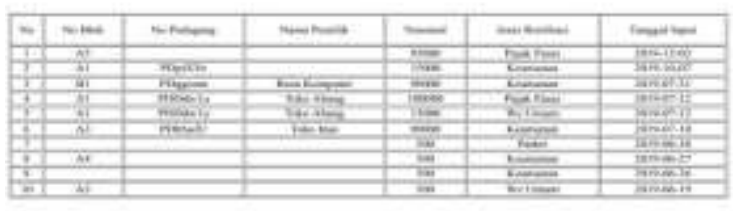

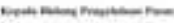

Gambar 5. Tampilan Laporan Retribusi

Pasar

6. Tampilan Laporan Bayar Sewa Toko

Merupakan Tampilan laporan pembayaran sewa toko

LAPORAN PEMBAYARAN SEWA TOKO

\begin{tabular}{|c|c|c|c|}
\hline$\infty$ & Saled & Merna Narrili & Statu formuvara \\
\hline 1 & AI & Asco Manninder & Seabis \\
\hline 2 & $\Omega^{2}$ & $\gamma_{s=1}$ & Sudith \\
\hline 3 & AI & & \\
\hline 4 & $M$ & & \\
\hline 3 & 25 & & \\
\hline A & $\overline{A B}$ & & \\
\hline 7 & A7 & & \\
\hline 8 & is & & \\
\hline 9 & $A v$ & & \\
\hline 16 & ANe & & \\
\hline
\end{tabular}

Gambar 6. Tampilan Laporan Pembayaran Sewa Toko

\section{KESIMPULAN}

Sistem ini memberikan kemudahan terhadap pengelola pasar dalam mengelola dan melakukan pendataan pada pasar. Dan dengan adanya sistem informasi, lebih mudah dalam mengelola data pedagang yang ada di pasar, mengelola retribusi pasar dan pembayaran sewa toko sehingga dapat memonitor pendapatan pasar melalui bagian tersebut.

Diharapkan pada Sistem Informasi Pengelolaan Retribusi Pasar Berbasis Web ini mengalami peningkatan versi dengan mengikuti perkembangan teknologi serta kebutuhan. Sistem Informasi Pengelolaan Pasar ini diharapakan dapat dibuat lebih menarik dengan penambahan menu GIS untuk memberikan peta lokasi dan kios pada pasar dengan jelas sehingga lebih memudahkan dalam mengelola pasar tersebut. Pembuatan menu tambahan untuk pendaftaran sebagai pedagang dan pembayaran retribusi serta sewa toko secara online.

\section{DAFTAR PUSTAKA}

Abdul Kadir. 2003. Pengenalan Sistem Informasi. Andi. Yogyakarta.

Kurniawan, F. (2017). Pengertian Sistem Secara Umum dan Menurut Para Ahli. Retrieved from fredikurniawan.com: http://fredikurniawan.com/pengertian-sistemsecara-umum-dan-menurut-para-ahli/ 
(20/01/2018). Di akses pada tanggal 20 Juni 2018

Murtiani, S., Subroto, I. M. I., \& Kurniadi, D. (2016). Sistem Informasi
Retribusi Pedagang Pasar Kabupaten Semarang. Jurnal Transistor Elektro dan Informatika, l(1),

47-59. 